\title{
Plasmodium falciparum GBP2 is a telomere- associated protein that binds to G-quadruplex DNA and RNA
}

6 Authors \& Addresses

7 James Edwards-Smallbone ${ }^{1+}$, Anders L. Jensen ${ }^{2+}$, Lydia E. Roberts ${ }^{2}$, Francis Isidore G.

8 Totanes $^{2}$, Sarah R. Hart ${ }^{3}$, Catherine J. Merrick ${ }^{2 *}$

$10{ }^{1}$ Centre for Applied Entomology and Parasitology, Faculty of Natural Sciences, Keele

11 University, Keele, Staffordshire, ST5 5BG, United Kingdom.

2Department of Pathology, Cambridge University, Tennis Court Road, Cambridge, CB2

14 1QP, United Kingdom.

${ }^{3}$ School of Medicine, Faculty of Medicine and Health Sciences, Keele University, Keele,

17 Staffordshire, ST5 5BG, United Kingdom.

+These authors contributed equally.

\section{*Corresponding author and lead contact}

23 Email: cjm48@cam.ac.uk (CJM) 


\section{SUMMARY}

In the early-diverging protozoan parasite Plasmodium, few telomere-binding proteins have been identified and several are unique. Plasmodium telomeres, like those of most eukaryotes, contain guanine-rich repeats that can form G-quadruplex structures. In model systems, quadruplex-binding drugs can disrupt telomere maintenance and some quadruplex-binding drugs are potent anti-plasmodial agents. Therefore, telomereinteracting and quadruplex-interacting proteins may offer new targets for anti-malarial therapy. Here, we report that $P$. falciparum GBP2 is such a protein. It was identified via 'Proteomics of Isolated Chromatin fragments', applied here for the first time in Plasmodium. In vitro, PfGBP2 binds specifically to G-rich telomere repeats in quadruplex form and it can also bind to G-rich RNA. In vivo, PfGBP2 partially colocalises with the known telomeric protein HP1 but is also found in the cytoplasm, probably due to its affinity for RNA. Consistently, its interactome includes numerous RNA-associated proteins. PfGBP2 is evidently a multifunctional DNA/RNA-binding factor in Plasmodium.

\section{INTRODUCTION}

Human malaria, caused by protozoan Plasmodium parasites, is responsible for widespread morbidity and almost half a million deaths each year (WHO, 2020). Plasmodium lies in an early-diverging lineage which differs greatly from model eukaryotic organisms: it is an obligate intracellular parasite that lives inside host cells for much of its lifecycle, and divides primarily by schizogony rather than conventional binary fission.

Plasmodium maintains its genome in conventional linear chromosomes, capped by telomeres that consist of a simple guanine-rich repeat (Figueiredo et al., 2000). These telomeres must be constantly maintained to prevent their degradation during the many replicative rounds of the parasite's lifecycle. However, Plasmodium lacks discernible homologues of almost all of the telomere-binding factors previously identified in model organisms (Zakian, 2012), which control telomere maintenance, recruit or suppress telomerase, enforce transcriptional silencing of adjacent genes via the 'telomere position effect' (Gottschling et al., 1990) and suppress the recombination or fusion of DNA ends. In Plasmodium the telomere repeat sequence differs slightly from that of the human host (GGGTT(T/C)A instead of GGGTTA), but it is nevertheless likely that specific proteins exist to cap telomeres, monitor their length, regulate their maintenance and mediate their nuclear clustering and tethering, since all these canonical features of telomere biology appear in Plasmodium (Bottius et al., 1998; Freitas-Junior et al., 2000).

The first telomeric protein characterized in Plasmodium was telomerase itself (Bottius et al., 1998; Figueiredo et al., 2005) and two new proteins were discovered more recently: a zinc-finger protein PfTRZ (Bertschi et al., 2017) and an ApiAP2 transcription

62 factor PfAP2Tel (Sierra-Miranda et al., 2017). Both are particular to Plasmodium

63 telomeres, emphasizing the unusual nature of the Plasmodium telosome. Identifying 
64 additional telomere-binding factors in Plasmodium could improve our understanding of telomere biology beyond model organisms.

Importantly, studying Plasmodium telomeres could also reveal potential new drug targets, since all single-celled eukaryotes must maintain their telomeres in order to survive. Accordingly, various telomere-targeting drugs that were designed as anti-cancer agents have also been tested against Plasmodium (De Cian et al., 2008; Harris et al., 2018). These drugs are frequently designed to target a particular DNA structure called the guanine-quadruplex (G4), which can form in single-stranded guanine-rich sequences such as telomere repeats. G4s occur at eukaryotic telomeres and play important roles in telomere maintenance - hence their potential as anti-cancer targets (Murat and Balasubramanian, 2014). We have reported that a G4-binding drug called quarfloxin kills Plasmodium parasites rapidly and potently in vitro (Harris et al., 2018), raising the possibility of repurposing it and/or other such drugs as anti-malarials.

Here, we aimed to identify and characterize novel telomere-binding proteins in Plasmodium falciparum, using the agnostic approach of pulling down fragments of telomeric chromatin and identifying the associated proteins by mass spectrometry. This method, called Proteomics of Isolated Chromatin fragments, or 'PICh', previously identified more than 80 telomere-binding components in human cells (Dejardin and Kingston, 2009). It was adapted to $P$. falciparum - a method that may prove useful in future for identifying other chromatin-domain-specific proteins - and it identified the protein PfGBP2 (PF3D7_1006800). PfGBP2 is an RRM-domain protein whose yeast homolog, 'G-strand Binding Protein 2', is known to bind to single-stranded telomeric DNA in S. cerevisiae (Lin and Zakian, 1994), as well as binding to mRNAs for nuclear/cytoplasmic shuttling (Windgassen and Krebber, 2003). We confirmed the interaction of PFGBP2 with Plasmodium telomere repeats and also with G-rich RNAs in vitro. Consistent with this, tagged PfGBP2 was found in vivo in the nucleus as well as the cytoplasm of blood-stage $P$. falciparum parasites and interacted with numerous RNAassociated proteins, as well as some DNA-associated proteins. Thus, it seems likely that PfGBP2 plays a role in telomere maintenance, via its binding to telomeric G4s, and also in RNA dynamics.

\section{RESULTS}

\section{A PICh protocol for Plasmodium parasites}

Relatively little is known about how Plasmodium telomeres are replicated and maintained,

98 making the identification of novel telosome components in Plasmodium a priority.

99 Telomere length appears to be a complex trait: there is striking variation in the average 100 length at which telomeres are maintained in different strains of $P$. falciparum, yet their 101 length is relatively stable per strain during in vitro culture (Fig. 1a, (Merrick et al., 2012)). 102 This suggests that the trait has a 'set-point' - perhaps enforced when new Plasmodium 103 strains are generated sexually within a mosquito - and both genetic and epigenetic 
104 factors may contribute to telomere maintenance. To investigate the proteins involved in 105 this phenomenon, we set out to identify new telosome components in the $P$. falciparum 106 parasite.

The published protocol for PICh in Hela cells was adapted for P. falciparum (Fig. 1b), using DNA probes adapted to the Plasmodium telomere sequence (GGGTT(T/C)A with $67 \% \mathrm{~T}, 33 \% \mathrm{C}$ at the variable position), and crosslinking the chromatin after releasing parasites from host erythrocytes and washing then thoroughly to reduce contamination from host haemoglobin. Parasite chromatin extracts were probed in parallel with either a telomere-repeat probe or a scrambled probe and the proteins thus purified were identified by mass spectrometry. Yields were initially very limited (a first experiment produced only five $P$. falciparum proteins, including histones and other highly-abundant proteins like elongation factor 1 alpha, which were largely similar in the telomere-probe and controlprobe conditions). However, a second experiment using the alternative method of gelaided rather than filter-aided sample preparation for mass spectrometry gave a much greater yield of over $30 P$. falciparum proteins. There remained a high representation of histones and other abundant proteins (Table S1), and indeed similar issues were reported when PfTRZ and PfAP2Tel were previously identified via a different methodology (pulldown from nuclear extract onto telomeric versus scrambled DNA probes). In these studies only 12 out of 109 (Bertschi et al., 2017) or 7 out of 100 (Sierra-Miranda et al., 2017) of the proteins identified were telomere-probe-specific, but bona fide telomere proteins could nevertheless be selected. Similarly, one interesting candidate protein emerged from the PICh dataset.

\section{PICh identifies PfGBP2 as a putative telomere-binding protein} PF3D7_1006800: a putative homologue of S. cerevisiae GBP2. PfGBP2 is a protein of 246 amino acids encoding two RNA Recognition Motif (RRM) domains. These domains are well-characterized to occur in proteins that bind to single-stranded nucleic acids, either DNA or RNA (Query et al., 1989). The RRM structure consists of two helices and four strands in an alpha/beta sandwich which can bind to a strand of nucleic acid, and indeed PFGBP2 was modelled with two RRM domains, joined by a less structured linker region (Fig. 2a). In contrast, ScGBP2 is a larger protein with three RRM domains, the third of which is divergent and acts instead as a protein-protein interaction domain (Martinez-Lumbreras et al., 2016) (Fig. 2b). This third domain is lacking in the $P$. falciparum homolog and both RRM domains in PFGBP2 are actually most homologous to RRM2 in ScGBP2, which is the principal nucleic-acid-binding domain (MartinezLumbreras et al., 2016) (Fig. 2c). 
144 proteomic studies, PfGBP2 is in the nuclear proteome, as expected (Oehring et al., 2012).

145 Overall, data from multiple sources including protein modelling, transcriptomics and 146 proteomics all supported the probability that PfGBP2, being nuclear, nucleic-acid-binding 147 and maximally expressed at replicative stages, could be a bona fide telomere protein.

\section{Recombinant PfGBP2 binds to G-rich telomere sequences}

To confirm that PfGBP2 can actually bind to telomeric DNA, we produced a recombinant version of the protein (Fig. 3a). Histidine-tagged PfGBP2, expressed in $E$. coli, could be purified primarily as a full-length protein of $\sim 35 \mathrm{kDa}$ (predicted MW of 34 kDa including tags; some breakdown products were also co-purified, probably as single RRM domains after degradation at the flexible region). Extracts containing PfGBP2 were then used in electrophoretic mobility shift assays (EMSAs) on a DNA oligonucleotide consisting of a series of G-rich telomere repeats. This DNA was clearly retarded due to protein binding, which was not the case with either a scrambled oligonucleotide or a sequence comprised of $A$ and $T$ bases only (Fig. 3b). Thus, PfGBP2 evidently has a tropism for G-rich DNA, and furthermore for G-triad motifs (e.g. GGGTTTA), since scrambling this sequence abrogated binding.

RRM-domain proteins commonly bind RNA as well as DNA, so we investigated whether PFGBP2 might also bind to RNA: EMSAs performed with G-rich telomere repeat RNA oligos showed that this was indeed the case (Fig. 3c). Unlike the behavior seen in the DNA EMSA, PfGBP2 was not efficiently competed off by unlabeled RNA, and was only partially competed off by unlabeled DNA.

\section{Recombinant PfGBP2 binds to G-quadruplex DNA}

Next, we sought to determine whether the G-rich telomere repeat sequence was actually folded into a G4 when bound to PfGBP2, since it was theoretically possible that the DNA would be bound either as a G4 or as a linear strand. Two independent assays showed that the Plasmodium telomere repeat sequences used here can indeed fold into

$172 \mathrm{G} 4 s$ in the presence of $\mathrm{K}^{+}$ions, which are required to stabilize quadruplex structures.

173 Figure 4 a shows a dot-blot with the G4-structure-specific antibody BG4 (Biffi et al., 2013), while figure $4 \mathrm{~b}$ shows fluorescent emission from a G4-specific dye, thioflavin T, which induces G4 folding and fluoresces strongly only when bound to a G4 (Mohanty et al., 2013; Renaud de la Faverie et al., 2014). In both these assays, two variants on the Plasmodium telomere repeat (GGGTT(T/C)A) were tested, with different representations at the variable T/C position ('G-rich 1' and 'G-rich 2', all oligonucleotides are listed in Table S2). Both variants behaved identically: when folded in the presence of $\mathrm{K}^{+}$they showed

180 strong binding to the G4-specific antibody and strong emission from thioflavin T. By 181 contrast, the equivalent treatment in the presence of $\mathrm{Li}^{+}$ions, which destabilize G4s, 182 yielded lower signals in both assays, similar to those of a control A/T-only sequence. We 
183 also confirmed that four G-triads were required to form a $\mathrm{G} 4$, because the same sequence truncated to just three repeats did not give a strong G4 signal in either assay.

Having confirmed the specificities of these two assays for G4s, the BG4 antibody was then added to the DNA EMSA, where it exerted an additional shift upon the oligoPfGBP2 complex, showing that the complex indeed contained G4 DNA (Fig. 4c). Finally, PfGBP2 was also able to interfere with thioflavin $T$ emission when added to a mixture of thioflavin T and DNA (Fig. 4d), whereas an irrelevant protein (bovine serum albumin) could not. This interference could potentially occur via PfGBP2 binding to the DNA and dampening the emission from the dye in its G4-bound form; alternatively, it could occur because PfGBP2 actually competes the dye off the G4 motif. In summary, multiple independent assays showed that PfGBP2 is a bona fide G4-binding protein.

\section{PfGBP2 is found in both the nucleus and cytoplasm in erythrocytic}

\section{parasites}

Having characterized PfGBP2 in silico and in vitro, we proceeded to investigate its properties in vivo. A gene knockout of PfGBP2 was not attempted because this was found to be very deleterious in a recent forward-genetics screen for essential genes in $P$. falciparum, (Zhang et al., 2018): PfGBP2 mutants had a fitness score of -2.5 , only slightly higher than -3 in telomerase reverse transcriptase (TERT) knockouts. Instead, overexpression of the PfGBP2 gene was attempted in 3D7 parasites, via a tagged version of the gene transfected in episomally in addition to the endogenous copy. No transgenic parasites were obtained after three separate transfections with two different plasmids, carrying PfGBP2 with two different C-terminal tags (HA and Ty) and two different selectable markers: this strongly suggested that overexpression of tagged PfGBP2 protein was also deleterious. Ultimately, in order to localize the PfGBP2 protein in bloodstage parasites, the endogenous gene was C-terminally tagged with a triple HA tag using the selection-linked integration system (Birnbaum et al., 2017). Correct tagging was confirmed by PCR and the tagged protein was detected in parasites by both western blot and immunofluorescence (Fig. 5).

Western blotting revealed PFGBP2-3HA in the nucleoplasm and chromatin-bound fractions of all erythrocytic parasite stages (Fig. 5a), as would be expected for a telomere-

214 binding protein, but it was also found in the cytoplasm at all stages, most prominently in trophozoites. Consistently, PfGBP2-3HA was detected by immunofluorescence in individual parasites as peri-nuclear foci which are characteristic of telomeric factors (Fig. 5b): these appeared at all stages but PfGBP2-3HA was always present in the parasite cytoplasm as well.

To further confirm that the peri-nuclear foci of PfGBP2-3HA did represent telomeres, the PfGBP2 gene was Ty-tagged in a line already expressing the wellcharacterised telomeric factor heterochromatin protein 1 (HP1) with an HA tag (Flueck et al., 2009) (Fig. 5c). The two tags, HP1-HA and PfGBP2-Ty, partially colocalised, 
223 particularly in late schizonts, with each merozoite bearing a perinuclear focus of both

224 GBP2 and HP1. At earlier stages, however, HP1 foci were discrete, whereas PfGBP2 225 was dispersed throughout the parasite (Fig. 5d). This was consistent with the 226 fractionation of these parasites showing that HP1 was entirely restricted to the nucleus 227 whereas PfGBP2 was not (Fig. 5c). The tropism of GBP2 for RNA as well as DNA may explain the widespread localization of this protein.

Finally, to define the binding sites of PfGBP2 throughout the genome, chromatin immunoprecipitation (ChIP) was attempted. A ChIP/dot-blot suggested that PfGBP2-3HA was modestly enriched on telomeric DNA (Fig. S1a), but ChIP-seq for either PfGBP23HA or PfGBP2-Ty failed to give signals significantly above background at any locus. This compared with strong signals from the established sub-telomeric protein HP1 (Flueck et al., 2009) that was co-expressed in the PfGBP2-Ty line. In a series of genedirected ChIP experiments (Fig. S1b), HP1 was enriched by over 50-fold at all subtelomeric loci compared to chromosome-internal loci, whereas PfGBP2 was enriched by only 2-fold at sub-telomeric and G4-encoding loci compared to chromosome-internal loci. This demonstrated that the ChIP experiment was conducted correctly but that PfGBP2 did not, in our hands, give a strong enough signal for a meaningful ChIP-seq experiment.

\section{The interactome of PfGBP2 suggests roles in both DNA and RNA}

\section{metabolism}

To learn more about the potential biological roles of PFGBP2, the HA-tagged protein was immunoprecipitated (IP) and its interactome was obtained via mass spectrometry. Duplicate IP experiments were conducted, yielding a total of 29 reproducible hits specific to PFGBP2 (i.e. absent from an identical control experiment using wildtype parasites) (Fig. 6A, Table S3). A larger group of 187 proteins appeared uniquely in just one of the two PfGBP2 IP experiments (Fig. 6B, Table S3).

Amongst the reproducible hits there was a clear preponderance of RNAassociated proteins. Gene ontology terms including 'cytosolic ribosome', 'ribonucleoprotein complex', and various terms concerning mRNA editing and base modification were enriched in the interactome (Fig. 6A, Table S4). A few DNA-binding

254 proteins were also represented, including a zinc-finger protein (PF3D7_1317400), but DNA-related GO terms were not strongly enriched overall, and the known telomeric proteins PfTRZ or PfAP2Tel did not appear. A broader analysis of all 187 putative PFGBP2-interacting proteins yielded similar results, i.e. a clear enrichment of RNAassociated proteins (Table S4), as well as a few DNA-associated proteins.

These results were compared with those of a recent study that used machine

260 learning to infer a proteome-wide interactome for $P$. falciparum (Hillier et al., 2019). This 261 reported that at least 17 of the top 50 interactors for PfGBP2 were RNA-associated 262 proteins, including several initiation factors and snRNP-associated proteins, while 5 out 
263 of 50 were DNA-associated proteins, including a DNA helicase, a DNA repair protein, a 264 transcription factor and the High Mobility Group protein HMGB1. Only 5 out of these 50 265 top interactors appeared as PfGBP2 interactors in one of our two datasets, including the 266 transcription factor (PF3D7_1426100) and PfHMGB1 (PF3D7_1202900). The latter 267 protein is particularly interesting because in human cells, it was recently reported to 268 interact with telomeric G4 DNA (Amato et al., 2019), raising the possibility that PfGBP2 269 and PfHMGB1 might cooperate at telomeric G4s. Overall, the interactome strongly 270 suggests that PfGBP2 is present in RNA-binding as well as DNA-binding complexes. 


\section{DISCUSSION}

273 This work set out to identify novel Plasmodium telosome components, and subsequently 274 to characterise the GBP2 protein in $P$. falciparum. This involved the development of a

275

276

277

278

279

280

281

282

283

284

285

286

287

288

289

290

291

292

293

294

295

296

297

298

299

300

301

302

303

304

305

306

307

308

309

310

311

'PICh' method to pull down sequence-specific chromatin fragments from $P$. falciparum: a method that may have applications in future studies. PICh did identify a new telosome component, but it did not identify telomerase or other Plasmodium-specific telosome proteins, PfTRZ (Bertschi et al., 2017) or PfAP2Tel (Sierra-Miranda et al., 2017), which were both discovered via DNA-mediated pulldowns from parasite extracts. Those two reports did not identify one another's proteins either, suggesting that no method is entirely comprehensive and that more proteins may be undiscovered. In PiCh, however, the proteins are identified directly from native chromatin rather than from protein extracts that were subsequently re-bound to DNA probes, so there is potential to identify different sets of proteins. In particular, PfGBP2 evidently targets the G-rich telomeric overhang, whereas PfTRZ and PfAP2Tel (Myb- and AP2-domain proteins) bind to double-stranded DNA. The PiCh technique may thus be better-placed to detect components of native telomeric chromatin that are not dsDNA-binders and are not pulled down by conventional DNA probes. Of note, however, a second study published during the preparation of this manuscript did identify PfGBP2 via pulldown from parasite extracts, using a Gquadruplex-forming DNA sequence as the probe (Gurung et al., 2020).

Unlike PfTRZ and PfAP2Tel, PfGBP2 is not unique to Plasmodium: homologues exist in eukaryotes including plants, yeast and humans, as well as other apicomplexans. In apicomplexans, GBP2 takes a short form with just two DNA-binding RRM domains. This is also the form found in plants, whereas in S. cerevisiae there is a third, divergent RRM domain which mediates protein-protein interaction with the THO/TREX mRNA export complex (Martinez-Lumbreras et al., 2016), and ScGBP2 accordingly has dual functions in telomere binding and mRNA metabolism. Dual roles for such proteins are not unusual: some hnRNPs also bind to both G-rich RNA and telomeric ssDNA, and play roles in both RNA metabolism and telomere stabilisation (Tanaka et al., 2007). Indeed, we present here the first evidence that PfGBP2 binds to G-rich RNA as well as DNA, and we also suggest that PfGBP2 overexpression may be lethal, as ScGBP2 overexpression is also lethal, owing to deregulated mRNA export (Windgassen and Krebber, 2003). Nevertheless, the mRNA shuttling role played by ScGBP2 is probably not directly conserved in $P$. falciparum, since ScGBP2 requires its third domain for recruitment to nascent mRNA via TREX (Hurt et al., 2004), and not all components of the THO/TREX complex have even been identified in Plasmodium (Tuteja and Mehta, 2010). Therefore, any interaction with RNA may be mediated differently in parasites.

By contrast, it is clear that the role in telomeric DNA binding is conserved among yeasts, plants and apicomplexans. In S. cerevisiae, GBP2 lacks an essential telomeric function: it does protect telomeric ssDNA (Pang et al., 2003) but telomeres can still be maintained in its absence, albeit with mislocalisation of the Rap1 protein (Konkel et al., 
312 1995). On the contrary, in plants, the telomere-binding role of GBP2 is essential. In 313 Nicotiana tabacum, its loss causes severe developmental and chromosomal 314 abnormalities with defective telomeres (Lee and Kim, 2010). PfGBP2 is more closely 315 homologous to the plant version than the yeast version, sharing $46 \%$ similarity with 316 NtGBP2, and the PfGBP2 gene was essential or near-essential in a $P$. falciparum 317 genome-wide screen (Zhang et al., 2018). However, in their recent report on PfGBP2, 318 Gurung and co-workers were able to achieve a knockout which surprisingly had no growth 319 defect, nor was telomere maintenance affected (Gurung et al., 2020). A viable P. berghei 320 GBP2 knockout has also been reported and although its telomeres were not assessed, this parasite line did grow slowly (Niikura et al., 2020).

All these data call into question the expectation that GBP2 might be essential in Plasmodium and might play a role in telomere maintenance. However, the knockouts reportedly achieved in both $P$. falciparum and $P$. berghei may have been nonhomogenous, since the genetic status of the knockout populations was not confirmed after long-term growth. A salient example in the literature reports the knockout of another essential telomeric protein, telomerase, via disruption of the TERT gene in $P$. berghei. Knockouts were briefly detected in bulk culture, but could never be cloned out before they were outgrown by healthier non-knockout parasites (Religa et al., 2014). This was probably because the telomeres in the knockout parasites quickly became critically degraded, so the authors concluded that PbTERT was essential. It would be interesting to establish whether outgrowth of non-knockout parasites could also occur if GBP2 knockout parasites are debilitated by telomere loss.

Whether or not the telomere-binding role of PfGBP2 is essential, the role clearly exists. On this point our work is consistent with that of Gurung et al., and also with a 2015 study (published in Spanish and not indexed via PubMed) which previously identified PfGBP2 in silico as a putative telosome component and confirmed that it binds specifically to G-rich telomere-repeat oligos in vitro (Calvo and Wasserman, 2015). The same property has been tested in other apicomplexans as well: Eimeria GBP2 was found at telomeres (via semi-quantitative ChIP-PCR (Zhao et al., 2014)), while Cryptosporidium GBP2 bound to telomeric DNA in vitro and specifically required its first RRM domain to do so (Liu et al., 2009). Our work goes further in examining the quadruplex-binding 343 capacity of PFGBP2: we conducted two independent assays to detect folded G4s in 344 PfGBP2-DNA complexes. The exact G4 binding mode of the protein is unknown, but if 345 PfGBP2 can directly compete with ThT to bind G4s (which is one explanation for the data 346 in figure 4d), then this would suggest an end-stacking mode, because thioflavin $T$ is 347 thought to end-stack onto the terminal G-quartet of a G4 (Mohanty et al., 2013). Further 348 biophysical studies would be needed to confirm this. Finally, our work also goes further 349 in exploring the binding of PFGBP2 to RNA as well as DNA G4s. An affinity for RNA 350 explains the broad cellular location of this protein, and is consistent with the presence of many RNA-binding proteins in the PfGBP2 interactome, 
The biological implications of PfGBP2's clear affinity for DNA/RNA G4s still warrant further study. Gurung et al. reported that the G4 affinity is not restricted to telomeres: the protein was initially identified via pulldown on a non-telomeric G4, and it was then found throughout the genome via ChIP-seq (Gurung et al., 2020), although surprisingly the original G4 sequence used in the pulldown did not appear in the ChIP results. These authors reported that PfGBP2 bound very broadly throughout the genome with an extreme enrichment of 500-2000 fold over input: this is an order of magnitude greater than that seen with the bona fide sub-telomeric protein HP1 (Flueck et al., 2009). By stark contrast, we were unable to obtain a meaningful ChIP signal, even when PfGBP2 was identically C-terminally tagged in a chromatin preparation from which HP1 could be ChIPed with over 50-fold enrichment. Since Gurung et al. did not perform a similar ChIP control, the disparity between these two very similar experiments remains unexplained. Nevertheless, if PfGBP2 does indeed bind very broadly to G-rich sequences throughout the $P$. falciparum genome, the protein could play interesting roles in G4 metabolism beyond telomeres.

Overall, the data presented here, together with the literature on GBP2 proteins across eukaryotes, indicate a triple role for PfGBP2 - in telomeric G4 binding, in pangenomic G4 binding, and in G4-RNA binding. PfGBP2 is the first G4-binding protein to be identified in Plasmodium, and only the third protein, beside telomerase, to be identified as part of the divergent telosome in Plasmodium.

\section{LIMITATIONS OF THE STUDY}

374 The full functional characterisation of this protein awaits further work. A mechanistic role 375 for PFGBP2 in RNA metabolism, such as RNA processing or shuttling, has not been 376 investigated, and nor has its exact role at telomeres (although a complementary paper 377 already reported no effect upon telomere length). In addition, although there is strong 378 evidence that this is a true G4-binding protein, its binding mode has not been evaluated, 379 nor has any preference for particular structures such as parallel vz antiparallel 380 quadruplexes.

\section{AUTHOR CONTRIBUTIONS}

383 JES - Designed, optimized and conducted PiCh experiments

384 ALJ - Conducted recombinant protein production, EMSA, ThT fluorescence, dot-

385 blotting, western blotting and co-immunoprecipitation experiments

386 LER - Cloned the expression vector and conducted recombinant protein production

387 FIGT - Designed, optimized and conducted ChIP

$388 \mathrm{SRH}-$ Coordinated and analysed data from mass spectrometry on PiCh samples 
CJM - Designed the study, conducted experiments (including Southern blotting, cloning, transfection and immunofluorescence assays), analysed data, made figures and wrote the manuscript.

\section{ACKNOWLEDGEMENTS \& FUNDING}

We acknowledge the Cambridge Centre for Proteomics and the Liverpool Centre for Proteome Research, particularly Philip Brownridge for expert assistance with PiCh mass spectrometry; Jerome Dejardin for helpful comments and advice regarding PICh; Till Voss (Swiss TPH) for the HP1-HA parasite line; Richard Bartfai and Jonas Gockel (Radboud University) for help with ChIP-seq; Christian Happi (Redeemers' University) and the group of Dyann Wirth (Harvard University) for supplying parasite genomic DNAs from Nigeria and Senegal. The work was supported by the UK Medical Research Council [grant MR/L008823/1 to CJM] and UK Biotechnology and Biological Sciences Research Council [grant BB/K009206/1 to CJM].

\section{DECLARATIONS OF INTEREST}

406 The authors declare no conflict of interest.

\section{FIGURE LEGENDS}

\section{Figure 1: Plasmodium telomeres vary in their set-point lengths}

(A) Telomere Restriction Fragment Southern blot showing variation in telomere lengths in geographically diverse strains of $P$. falciparum (K1, Thailand; 7G8, Brazil; D10, Papua New Guinea; P04.08, Senegal; AP041, Nigeria).

(B) Schematic showing the process of PICh in $P$. falciparum.

(B) Amino acid alignment of PfGBP2 with ScGBP2. Grey bars denotes the regions containing Prosite RRM motifs.

(C) Schematic showing the domain structure of ScGBP2 and PFGBP2. Table shows amino acid identity and similarity scores from pairwise alignments of the individual RRM domains: grey highlighted boxes show that both RRM domains from PFGBP2 score most highly against ScGBP2 RRM2.

\section{Figure 3: PfGBP2 binds to telomeric DNA and RNA sequences}


426 (A) Recombinant 6x His-tagged PfGBP2 (full-length protein marked with arrow), expressed in $E$. coli and purified via nickel resin. Coomassie-blue-stained gel and western blot against the $6 x$ His-tag. Images are representative of several independent preparations.

(B) EMSA assays with the indicated oligonucleotides and bacterial extract containing PfGBP2, or equivalent extract containing no recombinant protein in the control condition. 'Comp', unlabeled competitor DNA. Images are representative of several

433 independent experiments.

434 (C) EMSA assay as in (B), using RNA instead of DNA. Competition was attempted with an excess of either unlabeled RNA or unlabeled DNA.

Figure 4: PfGBP2 binds to G4-folded DNA

(A) Dot-blot of the indicated oligonucleotides probed with the G4-specific antibody BG4. Image is representative of triplicate experiments.

(B) Fluorescence emission from the indicated oligonucleotides in the presence of the complex at 0.5:1, 1:1 and 2:1 molar ratio of antibody to purified PfGBP2.

(D) Fluorescence emission from G-rich oligonucleotide 1 bound to thioflavin $T$, as in (B), with the addition of increasing quantities of purified PfGBP2 or the control protein BSA. Protein:DNA molar ratios between $0.25: 1$ and 2:1 were tested.

Figure 5: PfGBP2 is found in both the nucleus and cytoplasm in erythrocytic parasites

450 (A) Western blot of protein fractions (cyt, cytoplasm; nuc, nucleoplasm; chr, chromatinbound) from ring, trophozoite and schizont 3D7 parasites expressing PfGBP2-3HA. Parallel control blots show histone $\mathrm{H} 4$ (nuclear) and glyceraldehyde 3-phosphate dehydrogenase (GAPDH, cytoplasmic). Images are representative of several independent fractionation experiments.

(B) Representative immunofluorescence images of ring, trophozoite and schizont 3D7 parasites expressing PfGBP2-3HA, stained with an antibody against the HA tag and DAPI to identify parasite nuclei. Scale bar, $2 \mu \mathrm{m}$.

458 (C) Western blots as in (A): 3D7 parasites expressing PfGBP2-2Ty and HP1-3HA.

(D) Representative immunofluorescence images as in (B), parasites expressing

460 PfGBP2-2Ty and HP1-3HA.

Figure 6: PfGBP2 interacts primarily with RNA-associated proteins reproducibly in duplicate experiments but absent from the control experiment, with examples of representative proteins. 
466 (B) Venn diagram showing the larger number of PfGBP2-interacting proteins found in

467 only one duplicate experiment, with examples of representative proteins.

\section{MATERIALS AND METHODS}

\section{Parasite culture and transfection} the MR4 repository (www.beiresources.org). 3D7 was used for all experiments except the telomere Southern blots, which used genomic DNA from other strains. Parasites were maintained in vitro in human O+ erythrocytes at 4\% haematocrit in RPMI 1640 medium supplemented with $25 \mathrm{mM}$ HEPES (Sigma-Aldrich), $0.25 \%$ sodium bicarbonate, $50 \mathrm{mg} / \mathrm{L}$ hypoxanthine (Sigma-Aldrich), 0.25\% Albumax (Invitrogen) and 5\% heat-inactivated pooled human serum, using standard procedures (Trager and Jensen, 1976).

Transfections were carried out after synchronization with 5\% sorbitol and then maturation to highly synchronous late-stage trophozoites/schizonts. Transgenic parasites were generated by allowing these cultures to invade erythrocytes pre-loaded with 50 - $100 \mu \mathrm{g}$ plasmid DNA as previously described (Deitsch et al., 2001). Parasites were allowed to grow for 48 hours before being exposed to drug selection, and then maintained with 5nM WR99210 (Jacobus Pharmaceuticals). For pSLI-mediated gene tagging, transfectants were subsequently selected with neomycin, as previously described (Birnbaum et al., 2017), to select parasites carrying the genome-integrated construct. $2 \mu \mathrm{g} / \mathrm{ml}$ blasticidin (Invitrogen) was also used to select for simultaneous expression of HP1-3HA in the HP1-3HA+GBP2-2Ty line.

\section{Telomere restriction fragment Southern blotting}

Genomic DNA was extracted from parasites using the QIAamp DNA Blood Mini Kit (Qiagen), digested with restriction enzymes Alul, Ddel, Mboll and Rsal, then blotted with a probe specific for telomeres as described previously (Bottius et al., 1998; Figueiredo et al., 2002).

\section{Proteomics of Isolated Chromatin Segments (PICh)} PICh assays were carried out essentially as described by Dejardin and Kingston (Dejardin and Kingston, 2009), with Plasmodium-specific modifications. A full step-by-step PiCh method can be obtained from https://www.epigenesys.eu/images/stories/protocols. Briefly, parasite cultures were expanded and synchronized with two rounds of sorbitol treatment to yield $1 \mathrm{~L}$ of synchronous late-stage trophozoites at $9 \%$ parasitaemia. Parasitized cells were collected by centrifugation and washed in PBS-PMSF, prior to erythrocyte lysis by addition of saponin to $0.1 \%$. Free parasites were then collected by centrifugation and washed four times in PBS-PMSF, before being crosslinked for 30 mins 
505 in 3.7\% formaldehyde/PBS-PMSF. Thereafter samples were treated as previously 506 described (Dejardin and Kingston, 2009) with the following critical parameters: RNAse 507 incubation: $2 \mathrm{~h}$ at room temperature. Sonication: Total "on" time of $15 \mathrm{mins}(4 \times 7.5 \mathrm{~min})$, 50830 s on, 30s off. Chromatin preparations were split in two (1x target, 1x control) and 509 hybridized with $30 \mu$ l of probe per sample (a 50-fold molar excess). Probe sequences are

510 provided in Table S2. Probe-chromatin complexes were captured magnetically, washed, 511 eluted and then isolated by TCA precipitation. Protein pellets were de-crosslinked by 512 boiling in 2\% SDS, 0.5M 2-mercaptoethanol, 250mM Tris buffer for 30 mins.

514 PiCh protein digestion via filter/gel-aided sample preparation and 515 mass spectrometry

516 De-crosslinked proteins were subjected to either filter-aided sample preparation (FASP) 517 according to the methods of Mann and coworkers (Wisniewski et al., 2009), or gel-aided 518 sample preparation (GASP) following the methods of Fischer and Kessler (Fischer and 519 Kessler, 2015). In the FASP method, samples were processed using a FASP Protein 520 Digestion Kit (Expedeon, Cambridgeshire), following the manufacturer's procedure. 521 GASP was performed by adding acrylamide 40\% (w/v) (Sigma-Aldrich) 1:1 v/v to the 522 sample, enabling formation of protein-containing polyacrylamide plugs upon 523 polymerization using ammonium persulphate and TEMED (Sigma-Aldrich). Gel plugs 524 were then diced by spinning at 14,000 xg through plastic mesh, before being washed 525 using two successive washes with $6 \mathrm{M}$ urea and $100 \mathrm{mM}$ ammonium bicarbonate in 50 $526 \%$ acetonitrile, and subjected to in-gel digestion. Peptides extracted from gel pieces were 527 dried under vacuum, dissolved in $0.1 \%$ formic acid and run using a Q-Exactive hybrid 528 mass spectrometer (Thermo Fisher Scientific), coupled online to nanoflow HPLC. For both FASP and GASP-derived peptides, the mass spectrometer was operated in a 'top10' 530 mode, whereby the ten most abundant new precursors observed per survey scan are 531 subjected to product ion analysis by collisional dissociation (Michalski et al., 2011). 532 Product ion spectra were then subjected to parsing by Mascot Distiller using standard 533 settings for high resolution product ion spectra as recommended by the manufacturer, 534 and database searching using an in-house Mascot server (Matrix Sciences, London), 535 against a hybrid database comprised of sequences derived from $P$. falciparum (download 536 date 20th July 2015), alongside common contaminant proteins from artefactual sources 537 frequently seen in pulldown proteomics experiments (Mellacheruvu et al., 2013). Data 538 were compared using Scaffold Q+ (v. 4.3.3, Proteome Software, Portland IR).

\section{Protein modelling}

541 Structural modelling of PfGBP2 was conducted using I-TASSER (Iterative Threading 542 ASSEmbly Refinement) (Yang et al., 2015). Queries were submitted via the online server 543 (http://zhanglab.ccmb.med.umich.edu/l-TASSER/) and modelling was conducted ab initio 
544 without optional guide templates or specification of secondary structure. Queries were submitted in October 2018.

\section{Plasmid construction}

548 To clone the PfGBP2 (PF3D7_1006800) gene for recombinant protein production, the full-length transcript minus the stop codon was amplified by PCR from $P$. falciparum cDNA and cloned into the pET-28a+ expression vector between the BamHI and Xhol sites, resulting in a construct with dual $6 x \mathrm{His}$ tags at the $\mathrm{N}$ and $\mathrm{C}$ termini. To clone plasmids for 3' HA or Ty tagging of the endogenous PfGBP2 gene via the pSLI system, the latter half of the gene was cloned into a pSLI 3' HA tagging vector (Birnbaum et al., 2017) between the Notl and Kpnl sites. Subsequently, the 3' half of the gene downstream of an endogenous Bg/ll site, together with the HA tag, were excised and replaced by the same gene portion with a 2xTy tag (this fusion having been previously generated in an episomal overexpression vector which was not tolerated by 3D7 parasites). All primer sequences are provided in Table S2.

\section{Recombinant protein production}

The pET-28a+ expression construct was transferred into BL21(DE3)/pLys strain (Stratagene) and protein production was induced at $37^{\circ} \mathrm{C}$ with $1 \mathrm{mM}$ IPTG (isopropyl- $\beta$ D-thiogalactopyranoside) for $3 \mathrm{~h}$. Bacteria were lysed with Bugbuster reagent (Merck Millipore) plus complete protease inhibitors (Roche), and purification was conducted using gravity flow over nickel affinity resin (Thermo-Fisher Scientific) as previously described (North et al., 2005). Purified protein was further concentrated using Amicon Ultra Centrifugal Filter Units (Merck Millipore).

\section{Western blotting}

Parasite fractions for western blotting were prepared as previously described (Voss et al., 2002). Samples were loaded onto $4-12 \%$ polyacrylamide gels and electrophoresed at $100 \mathrm{~V}$ for 60 mins. Electrophoretic transfer to nitrocellulose membrane was carried out at $100 \mathrm{~V}$ for 60 mins. Membranes were blocked in TBST with 5\% milk protein and probed with the following antibodies: 1:2000 anti-Ty1 (Invitrogen), then 1:1500 goat anti-mouse IgG-HRP (Dako); 1:1000 anti-HA (Roche), then 1:1500 goat anti-rat IgG-HRP (Biolegend); anti-histone H4 (Abcam), then 1:1000 goat anti-rabbit IgG-HRP (Abcam); or 1:1000 13.3 anti-GAPDH (European Malaria Reagent Repository), then 1:1500 goat antimouse lgG-HRP (Dako). Membranes were washed for $3 \times 5$ mins in TBST after each antibody step. Clarity Western ECL substrate (Bio-Rad) was added for 3 mins and blots were imaged using a FluorChemM chemiluminescent detection camera (ProteinSimple).

Recombinant protein was blotted with anti-His antibody using the same method: 1:2000 mouse anti-tetra-His IgG (Qiagen); 1:1500 goat anti-mouse IgG-HRP (Dako). Coomassie staining of recombinant protein after gel electrophoresis was performed by 
addition of $0.1 \%$ Brilliant blue R-250 for 20 mins (Fisher), then de-staining in $40 \%$ methanol $10 \%$ glacial acetic acid.

\section{Electrophoretic Mobility Shift Assay (EMSA)}

EMSAs were optimized and performed using a LightShift optimization and control system (Thermo Scientific). Protein extracts containing PfGBP2, and control extracts lacking the recombinant protein, were made as above. Crude extracts in Bugbuster reagent were purified using HisPur Ni-NTA resin (Thermo Scientific) and run through a Poly-Prep Chromatography Column (BioRad) by gravity. Purified GBP2 protein extract was used for all EMSAs.

Oligonucleotides were labelled using a 3 ' biotin end-labelling kit (Thermo Scientific). Binding reactions were carried out at room temperature with $1 \mu \mathrm{g}$ of GBP2 in the presence of $50 \mathrm{ng}$ dldC. Reactions were pre-incubated for 5 mins prior to the addition of $20 \mathrm{fmol}$ of labelled probe, then incubated for a further 20 mins at room temperature. Unlabeled competitor oligonucleotides were added in 200 -fold excess relative to probe. Reactions were then run at $100 \mathrm{~V}$ on a cooled $0.5 \mathrm{x}$ TBE-acrylamide gel (4-12\% gradient) for 100 mins. Samples were blotted onto nylon membrane (Perkin Elmer) at $380 \mathrm{~mA}$ for 60 mins, crosslinked under UV $(125 \mathrm{~mJ})$ and then blocked, washed and developed using a LightShift chemiluminescent detection kit (Thermo Scientific). EMSA supershift assays were performed similarly, with prior $1 \mathrm{~h}$ incubation of the biotinylated oligonucleotide with the anti-G4 antibody BG4 (Merck Millipore).

\section{Dot blotting}

To allow G4 folding, DNA oligonucleotides were heated to $90^{\circ} \mathrm{C}$ for 5 mins before the addition of $100 \mu \mathrm{M}$ Tris buffer $\mathrm{pH} 7.8$ and $100 \mu \mathrm{M} \mathrm{KCl}$, then cooled from $90^{\circ} \mathrm{C}$ to room temperature at a rate of $5^{\circ} \mathrm{C} / 5 \mathrm{~min}$. Alternatively, oligonucleotides were folded in increasing concentrations of $\mathrm{LiCl}$ instead of $\mathrm{KCl}$, up to $1 \mathrm{M}$. $5 \mu \mathrm{l}$ of oligonucleotides $(1 \mu \mathrm{M})$ were then spotted on to nitrocellulose membrane (Perkin Elmer) and crosslinked under UV (125mJ) for 5 mins. Membranes were washed and blocked as per western blotting protocol and probed with 1:1500 BG4 (Merck Millipore), 1:1500 DYKDDDK tag (anti-flag, Cell Signalling), and 1:1500 Goat anti-rabbit IgG-HRP (Abcam).

\section{Thioflavin T fluorescence assay}

Oligonucleotides at $20 \mu \mathrm{M}$ were treated with $\mathrm{KCl}$ or $\mathrm{LiCl}$ as above for dot blotting, then mixed with Thioflavin T (Sigma Aldrich) at a final concentration of $80 \mu \mathrm{M}$ and incubated at room temperature for 5 mins. $40 \mu \mathrm{l}$ of each oligonucleotide mixture was transferred in triplicate to the wells of a 96 well black, Uclear plate (Greiner), and analyzed using a FLUOstar Omega plate reader (BMG Labtech) at Ex. 420nm, Em. 480nm. PfGBP2 
622 competition assays were performed in the same way, with the addition of increasing

623 concentrations of purified PfGBP2, or BSA as a control, prior to the addition of ThT.

\section{Immunofluorescence}

626 Parasitized erythrocytes were smeared onto microscope slides and fixed in 4\% 627 formaldehyde/PBS for 10 mins, rinsed twice in PBS, treated with $0.03 \%$ triton/PBS for 10 628 mins, blocked with 1\% BSA/PBS for 30 mins, then incubated with the following antibodies: 629 1:500 anti-Ty1 (Invitrogen), then 1:1000 Alexa Fluor 546-conjugated anti-rat IgG (Thermo 630 Fisher Scientific); and/or 1:500 anti-HA (Roche), then 1:1000 Alexa Fluor 488-conjugated 631 anti-rat IgG (Thermo Fisher Scientific). Slides were washed for $3 \times 5$ mins in PBS after 632 each antibody step and in the penultimate wash $2 \mu \mathrm{g} / \mathrm{ml} 4$ ',6-diamidino-2-phenylindole 633 (DAPI) (Molecular Probes) was added. Slides were mounted with ProLong Diamond 634 antifade mountant (Thermo Fisher Scientific) and imaged with a Zeiss LSM700 Confocal 635 Microscope.

\section{ChIP-seq}

638 Chromatin preparation: Cultures of 1.6-3.6×109 sorbitol-synchronized parasites at 30-36 639 hpi were used for ChIP. Chromatin was crosslinked with $1 \%$ formaldehyde in culture 640 media for 10 minutes at $37^{\circ} \mathrm{C}$, then quenched with glycine at a final concentration of 0.125 M. Parasites were extracted by lysis with $0.05 \%$ saponin in PBS. Nuclei were extracted 642 by gentle homogenisation in cell lysis buffer $(10 \mathrm{mM}$ Tris $\mathrm{pH} 8.0,3 \mathrm{mM} \mathrm{MgCl}, 0.2 \%$ NP643 40, 1x Pierce protease inhibitor (Thermo Fisher)) and centrifugation at 2000 rpm for 10 644 minutes in $0.25 \mathrm{M}$ sucrose cushion in cell lysis buffer. Harvested nuclei were snap-frozen 645 in $20 \%$ glycerol in cell lysis buffer. Thawed nuclei were resuspended in sonication buffer 646 (50mM Tris- $\mathrm{HCl}, 1 \%$ SDS, 10mM EDTA, 1x protease inhibitor (Sigma-Aldrich), $\mathrm{pH} 8.0$ ) 647 and sonicated for 20-24 cycles of 30s ON, 30s OFF (setting high, BioruptorTM Next Gen, 648 Diagenode) (Fraschka et al., 2018).

$649 \quad$ Chromatin immunoprecipitation: Each ChIP reaction was set up with $500 \mathrm{ng}$ 650 sonicated chromatin incubated in incubation buffer $(0.15 \%$ SDS, $1 \%$ Triton-X100, 150mM $651 \mathrm{NaCl}, 1 \mathrm{mM}$ EDTA, 0.5mM EGTA, 1x protease inhibitor (Sigma-Aldrich), $20 \mathrm{mM}$ HEPES, $652 \mathrm{pH} 7.4$ ) with either $400 \mathrm{ng}$ of $\alpha-\mathrm{HA}$ (Roche 12158167001) or $1 \mu \mathrm{l} \alpha-\mathrm{Ty}$ (BB2, in-house 653 hybridoma supernatant), together with $10 \mu \mathrm{L}$ protA and $10 \mu \mathrm{L}$ protG Dynabeads 654 suspension (Thermo Fisher Scientific). For each sample, eight ChIP reactions were 655 prepared and incubated overnight rotating at $4{ }^{\circ} \mathrm{C}$. Beads were washed twice with wash 656 buffer 1 (0.1\% SDS, 0.1\% DOC, 1\% Triton-X100, $150 \mathrm{mM} \mathrm{NaCl,} 1 \mathrm{mM}$ EDTA, $0.5 \mathrm{mM}$ 657 EGTA, $20 \mathrm{mM}$ HEPES, pH 7.4), once with wash buffer $2(0.1 \%$ SDS, $0.1 \%$ DOC, $1 \%$ 658 Triton-X100, 500 mM NaCl, 1 mM EDTA, 0.5 mM EGTA, 20 mM HEPES, pH 7.4), once 659 with wash buffer $3(250 \mathrm{mM} \mathrm{LiCl}, 0.5 \%$ DOC, 0.5\% NP-40, 1 mM EDTA, $0.5 \mathrm{mM}$ EGTA, $66020 \mathrm{mM}$ HEPES, pH 7.4) and twice with wash buffer 4 (1 mM EDTA, $0.5 \mathrm{mM}$ EGTA, 20 $661 \mathrm{mM}$ HEPES, $\mathrm{pH}$ 7.4). Each wash step was performed for $5 \mathrm{~min}$ at $4^{\circ} \mathrm{C}$ while rotating. 
662 Immunoprecipitated chromatin was eluted in elution buffer (1\% SDS, 0.1M NaHCO 3 ) at

663 room temperature for $20 \mathrm{~min}$. The eluted chromatin samples and the corresponding input 664 samples (sonicated input chromatin containing 500 ng DNA) were de-crosslinked in 1\% $665 \mathrm{SDS} / 0.1 \mathrm{M} \mathrm{NaHCO}_{3} / 1 \mathrm{M} \mathrm{NaCl}$ at $65^{\circ} \mathrm{C}$ for at least $4 \mathrm{~h}$ while shaking, followed by column 666 purification (PCR Purification Kit, Qiagen) and elution in 200ul EB buffer.

Quantitative PCR: qPCRs were performed with $5 \mu \mathrm{L}$ ChIP-ed DNA against a 10x 668 dilution series of input DNA using $\mathrm{iQ}^{\mathrm{TM}}$ SYBR Green Supermix (Biorad) together with 669 primers (Table S2) mixed according to manufacturers' instructions on a C1000 Touch 670 CFX96 Real-Time System (Biorad).

671

\section{Co-immunoprecipitation and mass spectrometry} $800 \mathrm{ml}$ of 3D7 WT and 3D7 GBP2-3HA cultures were saponin-treated to release the parasites (1-2 × 10 ${ }^{10}$ parasites per sample, conducted in biological duplicate for GBP2). Parasites were re-suspended in lysis buffer $(1 \%$ Triton, $50 \mathrm{mM} \mathrm{HEPES,} 150 \mathrm{mM} \mathrm{NaCl}$, $1 \mathrm{mM}$ EDTA) and subjected to a freeze-thaw cycle three times, before treating with 1 unit of DNase 1 for 10 mins at $37^{\circ} \mathrm{C}$ (Thermo Fisher Scientific). Samples were then centrifuged for 30 mins at $4^{\circ} \mathrm{C}$ at 14500 rcf. Supernatant was added to Protein $\mathrm{G}$ magnetic beads (Pierce) pre-washed three times in wash buffer $(0.1 \%$ Triton, 50mM HEPES, 150mM $\mathrm{NaCl}$ ) and incubated for $1 \mathrm{~h}$ at $4^{\circ} \mathrm{C}$. Magnetic beads were removed by magnet and $1 \mathrm{mg} / \mathrm{ml}$ of anti-HA antibody (Roche) was added to the proteins for incubation overnight at $4^{\circ} \mathrm{C}$. Following incubation, a new aliquot of Protein $\mathrm{G}$ magnetic beads was washed, added to the samples and incubated for $1 \mathrm{~h}$ at $4^{\circ} \mathrm{C}$. Beads were again removed by magnet. Proteins were eluted by incubating in $30 \mu \mathrm{l}$ of $0.5 \mathrm{mg} / \mathrm{ml}$ Influenza Hemagglutinin (HA) Peptide (Stratech Scientific) dissolved in elution buffer $(0.1 \mathrm{M}$ Tris $\mathrm{pH} 7.4,150 \mathrm{mM} \mathrm{NaCl}$, $0.1 \%$ SDS, $0.5 \%$ NP40) and $1 \mu$ l of $0.1 \mathrm{M} \mathrm{DTT}$ (Invitrogen) was added to samples. Eluted protein samples were boiled in $4 x$ sample loading buffer (Invitrogen) for 10 mins at $90^{\circ} \mathrm{C}$. Samples were loaded onto a 4-12\% polyacrylamide gel (BioRad) and electrophoresed at $150 \mathrm{~V}$ for 10 mins, until the sample had run through the stacking wells.

Protein-containing gel was excised and cut into $1 \mathrm{~mm}^{2}$ pieces, destained, reduced using DTT, alkylated using iodoacetamide and subjected to enzymatic digestion with sequencing grade trypsin (Promega, Madison, WI, USA) overnight at $37^{\circ} \mathrm{C}$. After digestion, the supernatant was pipetted into a sample vial and loaded onto an autosampler for automated LC-MS/MS analysis.

LC-MS/MS experiments were performed using a Dionex Ultimate 3000 RSLC nanoUPLC system (Thermo Fisher Scientific) and a $Q$ Exactive Orbitrap mass 697 spectrometer (Thermo Fisher Scientific). Separation of peptides was performed by 698 reverse-phase chromatography at a flow rate of $300 \mathrm{~nL} / \mathrm{min}$ and a Thermo Scientific 699 reverse-phase nano Easy-spray column (Thermo Scientific PepMap C18, $2 \mu \mathrm{m}$ particle 700 size, 100A pore size, $75 \mu \mathrm{m}$ i.d. x $50 \mathrm{~cm}$ length). Peptides were loaded onto a pre-column 701 (Thermo Scientific PepMap 100 C18, $5 \mu \mathrm{m}$ particle size, 100A pore size, 300 $\mu \mathrm{m}$ i.d. $x$ 
702

703

704

705

706

707

708

709

710

711

712

713

714

715

716

717

718

719

720

721

722

723

724

725

726

727

728

729

730

731

732

733

734

735

736

737

738

739

740

741

$5 \mathrm{~mm}$ length) from the Ultimate 3000 autosampler with $0.1 \%$ formic acid for 3 mins at a flow rate of $15 \mu \mathrm{L} / \mathrm{min}$. After this period, the column valve was switched to allow elution of peptides from the pre-column onto the analytical column. Solvent $A$ was water $+0.1 \%$ formic acid and solvent $B$ was $80 \%$ acetonitrile, $20 \%$ water $+0.1 \%$ formic acid. The linear gradient employed was $2-40 \%$ B in 90 mins (the total run time including column washing and re-equilibration was 120 mins).

The LC eluant was sprayed into the mass spectrometer by means of an Easyspray source (Thermo Fisher Scientific Inc.). All $m / z$ values of eluting ions were measured in an Orbitrap mass analyzer, set at a resolution of 35000 and scanned between $\mathrm{m} / \mathrm{z} 380$ 1500. Data dependent scans (Top 20) were employed to automatically isolate and generate fragment ions by higher energy collisional dissociation (HCD, Normalised collision energy (NCE):25\%) in the HCD collision cell and measurement of the resulting fragment ions was performed in the Orbitrap analyser, set at a resolution of 17500 . Singly charged ions and ions with unassigned charge states were excluded from being selected for MS/MS and a dynamic exclusion of 60 seconds was employed.

Post-run, all MS/MS data were converted to mgf files and the files were then submitted to the Mascot search algorithm (Matrix Science, London UK, version 2.6.0) and searched against a common contaminants database (125 sequences; 41129 residues); and the CCP_Plasmodium_falciparum Plasmodium_falciparum_20190315 (5449 sequences; 4173922 residues) database. Variable modifications of oxidation (M) and deamidation (NQ) were applied as well a fixed modification of carbamidomethyl (C). The peptide and fragment mass tolerances were set to $20 \mathrm{ppm}$ and $0.1 \mathrm{Da}$, respectively. A significance threshold value of $p<0.05$ and a peptide cut-off score of 20 were also applied.

Data were then analysed using MaxQuant software version 1.6.17.0 (Elias and Gygi, 2007). Files were searched against Plasmodium falciparum 3D7 PlasmoDB-50 annotated proteins database (downloaded February 2021). Protein N-terminal acetyl and methionine oxidation were set as variable modifications, whilst cysteine carbidomethylation was a fixed modifier. C-terminal arginine was set as the enzyme specificity and trypsin as the protease. Minimum peptide length was 7 amino acids and maximum for peptide recognition was $4600 \mathrm{Da}$.

\section{GO enrichment analysis}

The analysis tool in PlasmoDB (Aurrecoechea et al., 2009) was used to obtain GO terms for all gene IDs encoding proteins found by co-immunoprecipitation. Enrichment of GO terms versus their representation in the whole genome was calculated within PlasmoDB, with a cutoff of $\mathrm{p}=0.05$ for statistically significant enrichment. Correction for multiple comparisons was conducted by both Benjamini-Hochberg FDR and the more stringent Bonferroni method, and $\mathrm{GO}$ terms with $p$-values remaining below 0.05 were considered to be enriched. 


\section{Supplementary Figures and Tables}

743

744

745

746

747

748

749

750

751

752

753

754

755

756

757

758

759

760

761

762

763

764

765

766

767

768

769

770

771

772

773

774

775

776

777

778

779

780

\section{S1 Figure. ChIP on PfGBP2}

(A) Dotblots of chromatin immunoprecipitated with antibodies to PFGBP2-3HA or to histone H4. Fold enrichment over input is shown. Telomere sequence is enriched by $\sim 2 x$ with antibody to PfGBP2-HA as well as antibody to histone $\mathrm{H} 4$, whereas a control nontelomeric gene is detected only in histone ChIP and is not enriched in HA ChIP.

(B) Examples of ChIP data from the PfGBP2-Ty line which co-expresses PfHP1-HA. Genome-wide ChIP-seq conducted in duplicate on this line, and also on the PfGBP2-3HA line, failed to give signals significantly above background (data not shown). To confirm the validity of the ChIP procedure using the validated chromatin protein PAHP1 as a control, ChIP was conducted with a selection of individual primer pairs directed to telomere repeats, subtelomeric genes, G-quadruplex-encoding genes, or chromosomeinternal genes. Representative data from one of two duplicate experiments are shown. PAHP1-HA, as expected, was enriched by $>50$-fold at sub-telomeric loci compared to chromosome-internal loci when it was immunoprecipitated with either anti-HA-tag or antiHP1 antibodies. By contrast, PfGBP2-Ty, present in the same parasites, was not strongly enriched at any locus: the mean enrichment at sub-telomeric and G4-encoding genes compared to non-telomeric genes was only 2.4-fold.

\section{S1 Table. Protein sequence matching data from FASP and GASP analysis of PICh extracts.}

Control (Ctl) and Target data from FASP (experiment 1) are compared to a second dataset obtained via GASP (experiment 2) using Scaffold, with a 95\% threshold for proteins and peptides, and a minimum of two peptides/hit. 'Exclusive Unique Peptide Count' is shown for each sample. Searches were performed using Mascot against a hybrid database containing sequences derived from Plasmodium falciparum (download date $20^{\text {th }}$ July 2015), combined with common contaminant proteins (CRAP, download date $30^{\text {th }}$ January 2015 and contaminants, download date $13^{\text {th }}$ July 2012, both downloaded from Matrix Science). No Plasmodium peptides were observed in the control GASP experiment, possibly due to a technical error, although they were detected in the preceding FASP experiment.

\section{S2 Table. Table of oligonucleotide sequences}

In PICh probes, 'C18' refers to the flexible linker region. Locked Nucleic Acid (LNA) bases are in capitals. ' $y$ ' is a $67 \% \mathrm{~T}, 33 \% \mathrm{C}$ custom base mix, designed to mimic the variable position in the Plasmodium telomere repeat (GGGTT(T/C)A) where the ratio is approx. $67 \%$ T: $33 \%$ C. 


\section{S3 Table. Proteins immunoprecipitated with PfGBP2}

Tab 1 shows all protein hits from duplicate anti-HA immunoprecipitations of PfGBP2-3HA, after any proteins also found in a control IP experiment from wildtype parasites have been screened out. Tab 2 shows the subset of proteins that were reproducibly found in both PfGBP2-3HA immunoprecipitations. Tab 3 shows proteins found uniquely in the control IP. GO terms for each hit are listed in the classes 'cellular component', 'biological function' and 'molecular process'.

\section{S4 Table. GO terms enriched amongst proteins immunoprecipitated} with PfGBP2

Enriched GO terms in the classes 'cellular component', 'biological function' and 'molecular process' are shown for the reproducible PfGBP2 interactors, and also for total set of PfGBP2 interactors found in at least one IP experiment. GO terms with statistically significant enrichment after correction for multiple comparisons are highlighted in yellow. Terms associated with RNA are in red text, and with DNA in blue text.

\section{REFERENCES}

Amato, J., Cerofolini, L., Brancaccio, D., Giuntini, S., Iaccarino, N., Zizza, P., Iachettini, S., Biroccio, A., Novellino, E., Rosato, A., et al. (2019). Insights into telomeric G-quadruplex DNA recognition by HMGB1 protein. Nucleic acids research 47, 9950-9966. Aurrecoechea, C., Brestelli, J., Brunk, B.P., Dommer, J., Fischer, S., Gajria, B., Gao, X., Gingle, A., Grant, G., Harb, O.S., et al. (2009). PlasmoDB: a functional genomic database for malaria parasites. Nucleic acids research 37, D539-543. Bertschi, N.L., Toenhake, C.G., Zou, A., Niederwieser, I., Henderson, R., Moes, S., Jenoe, P., Parkinson, J., Bartfai, R., and Voss, T.S. (2017). Malaria parasites possess a telomere repeatbinding protein that shares ancestry with transcription factor IIIA. Nat Microbiol 2, 17033. Biffi, G., Tannahill, D., McCafferty, J., and Balasubramanian, S. (2013). Quantitative visualization of DNA G-quadruplex structures in human cells. Nature Chemistry 5, 182-186. Birnbaum, J., Flemming, S., Reichard, N., Soares, A.B., Mesen-Ramirez, P., Jonscher, E., Bergmann, B., and Spielmann, T. (2017). A genetic system to study Plasmodium falciparum protein function. Nature methods $14,450-456$. Bottius, E., Bakhsis, N., and Scherf, A. (1998). Plasmodium falciparum telomerase: de novo telomere addition to telomeric and nontelomeric sequences and role in chromosome healing. Molecular and cellular biology 18, 919-925. Calvo, E.T., and Wasserman, M.L. (2015). PfGBP: una proteína de unión al telómero de Plasmodium falciparum. Revista Colombiana de Química 44, 5-10. De Cian, A., Grellier, P., Mouray, E., Depoix, D., Bertrand, H., Monchaud, D., Teulade-Fichou, and quadruplex targeting by small compounds. Chembiochem 9, 2730-2739. 
Deitsch, K., Driskill, C., and Wellems, T. (2001). Transformation of malaria parasites by the spontaneous uptake and expression of DNA from human erythrocytes. Nucleic acids research 29, 850-853.

Dejardin, J., and Kingston, R.E. (2009). Purification of proteins associated with specific genomic Loci. Cell 136, 175-186. Elias, J.E., and Gygi, S.P. (2007). Target-decoy search strategy for increased confidence in largescale protein identifications by mass spectrometry. Nature methods 4, 207-214. Figueiredo, L.M., Freitas-Junior, L.H., Bottius, E., Olivo-Marin, J.C., and Scherf, A. (2002). A central role for Plasmodium falciparum subtelomeric regions in spatial positioning and telomere length regulation. The EMBO journal 21, 815-824. structure of Plasmodium falciparum chromosome ends. Molecular and biochemical parasitology 106, 169-174.

Figueiredo, L.M., Rocha, E.P., Mancio-Silva, L., Prevost, C., Hernandez-Verdun, D., and Scherf, A. (2005). The unusually large Plasmodium telomerase reverse-transcriptase localizes in a discrete compartment associated with the nucleolus. Nucleic acids research 33, 1111-1122. Fischer, R., and Kessler, B.M. (2015). Gel-aided sample preparation (GASP)--a simplified method for gel-assisted proteomic sample generation from protein extracts and intact cells. Proteomics 15, 1224-1229.

Flueck, C., Bartfai, R., Volz, J., Niederwieser, I., Salcedo-Amaya, A.M., Alako, B.T., Ehlgen, F., Ralph, S.A., Cowman, A.F., Bozdech, Z., et al. (2009). Plasmodium falciparum heterochromatin protein 1 marks genomic loci linked to phenotypic variation of exported virulence factors. PLoS pathogens 5, e1000569.

Fraschka, S.A., Filarsky, M., Hoo, R., Niederwieser, I., Yam, X.Y., Brancucci, N.M.B., Mohring, F., Mushunje, A.T., Huang, X., Christensen, P.R., et al. (2018). Comparative Heterochromatin Profiling Reveals Conserved and Unique Epigenome Signatures Linked to Adaptation and Development of Malaria Parasites. Cell host \& microbe 23, 407-420 e408. Freitas-Junior, L.H., Bottius, E., Pirrit, L.A., Deitsch, K.W., Scheidig, C., Guinet, F., Nehrbass, U., Wellems, T.E., and Scherf, A. (2000). Frequent ectopic recombination of virulence factor genes in telomeric chromosome clusters of P. falciparum. Nature 407, 1018-1022. Gottschling, D.E., Aparicio, O.M., Billington, B.L., and Zakian, V.A. (1990). Position effect at S. cerevisiae telomeres: reversible repression of Pol II transcription. Cell 63, 751-762.

Gurung, P., Gomes, A.R., Martins, R.M., Juranek, S.A., Alberti, P., Mbang-Benet, D.E., Urbach, S., Gazanion, E., Guitard, V., Paeschke, K., et al. (2020). PfGBP2 is a novel G-quadruplex binding protein in Plasmodium falciparum. Cellular microbiology, e13303. Harris, L.M., Monsell, K.R., Noulin, F., Famodimu, M.T., Smargiasso, N., Damblon, C., Horrocks, P., and Merrick, C.J. (2018). G-Quadruplex DNA Motifs in the Malaria Parasite Plasmodium falciparum and Their Potential as Novel Antimalarial Drug Targets. Antimicrobial agents and chemotherapy 62.

860 Hillier, C., Pardo, M., Yu, L., Bushell, E., Sanderson, T., Metcalf, T., Herd, C., Anar, B., Rayner, 861 J.C., Billker, O., et al. (2019). Landscape of the Plasmodium Interactome Reveals Both Conserved and Species-Specific Functionality. Cell Rep 28, 1635-1647 e1635.

866

Hurt, E., Luo, M.J., Rother, S., Reed, R., and Strasser, K. (2004). Cotranscriptional recruitment of the serine-arginine-rich (SR)-like proteins Gbp2 and Hrb1 to nascent mRNA via the TREX complex. Proceedings of the National Academy of Sciences of the United States of America 101, 1858-1862. 
Konkel, L.M., Enomoto, S., Chamberlain, E.M., McCune-Zierath, P., Iyadurai, S.J., and Berman, J. (1995). A class of single-stranded telomeric DNA-binding proteins required for Rap1p localization in yeast nuclei. Proceedings of the National Academy of Sciences of the United States of America 92, 5558-5562. Lee, Y.W., and Kim, W.T. (2010). Tobacco GTBP1, a homolog of human heterogeneous nuclear ribonucleoprotein, protects telomeres from aberrant homologous recombination. Plant Cell 22, 2781-2795. Lin, J.J., and Zakian, V.A. (1994). Isolation and characterization of two Saccharomyces cerevisiae genes that encode proteins that bind to (TG1-3)n single strand telomeric DNA in vitro. Nucleic acids research 22, 4906-4913. Cryptosporidium parvum protein that binds single-stranded G-strand telomeric DNA. Molecular and biochemical parasitology $165,132-141$. Martinez-Lumbreras, S., Taverniti, V., Zorrilla, S., Seraphin, B., and Perez-Canadillas, J.M. (2016). Gbp2 interacts with THO/TREX through a novel type of RRM domain. Nucleic acids research 44, 437-448. Mellacheruvu, D., Wright, Z., Couzens, A.L., Lambert, J.P., St-Denis, N.A., Li, T., Miteva, Y.V., Hauri, S., Sardiu, M.E., Low, T.Y., et al. (2013). The CRAPome: a contaminant repository for affinity purification-mass spectrometry data. Nature methods 10, 730-736.

Merrick, C.J., Huttenhower, C., Buckee, C., Amambua-Ngwa, A., Gomez-Escobar, N., Walther, M., Conway, D.J., and Duraisingh, M.T. (2012). Epigenetic dysregulation of virulence gene expression in severe Plasmodium falciparum malaria. The Journal of infectious diseases 205, 1593-1600.

Michalski, A., Damoc, E., Hauschild, J.P., Lange, O., Wieghaus, A., Makarov, A., Nagaraj, N., Cox, J., Mann, M., and Horning, S. (2011). Mass spectrometry-based proteomics using Q Exactive, a high-performance benchtop quadrupole Orbitrap mass spectrometer. Molecular \& cellular proteomics : MCP 10, M111 011015.

Mohanty, J., Barooah, N., Dhamodharan, V., Harikrishna, S., Pradeepkumar, P.I., and Bhasikuttan, A.C. (2013). Thioflavin $T$ as an efficient inducer and selective fluorescent sensor for the human telomeric G-quadruplex DNA. J Am Chem Soc 135, 367-376.

Murat, P., and Balasubramanian, S. (2014). Existence and consequences of G-quadruplex structures in DNA. Curr Opin Genet Dev 25, 22-29.

Niikura, M., Fukutomi, T., Fukui, K., Inoue, S.I., Asahi, H., and Kobayashi, F. (2020). G-strand binding protein 2 is involved in asexual and sexual development of Plasmodium berghei. Parasitol Int 76, 102059.

North, B.J., Schwer, B., Ahuja, N., Marshall, B., and Verdin, E. (2005). Preparation of enzymatically active recombinant class III protein deacetylases. Methods 36, 338-345.

Oehring, S.C., Woodcroft, B.J., Moes, S., Wetzel, J., Dietz, O., Pulfer, A., Dekiwadia, C., Maeser, P., Flueck, C., Witmer, K., et al. (2012). Organellar proteomics reveals hundreds of novel nuclear proteins in the malaria parasite Plasmodium falciparum. Genome biology 13, R108.

Painter, H.J., Chung, N.C., Sebastian, A., Albert, I., Storey, J.D., and Llinas, M. (2018). Genomewide real-time in vivo transcriptional dynamics during Plasmodium falciparum blood-stage development. Nature communications 9, 2656.

Pang, T.L., Wang, C.Y., Hsu, C.L., Chen, M.Y., and Lin, J.J. (2003). Exposure of single-stranded telomeric DNA causes G2/M cell cycle arrest in Saccharomyces cerevisiae. The Journal of biological chemistry 278, 9318-9321. 
913 Query, C.C., Bentley, R.C., and Keene, J.D. (1989). A common RNA recognition motif identified 914 within a defined U1 RNA binding domain of the 70K U1 snRNP protein. Cell 57, 89-101.

915 Religa, A.A., Ramesar, J., Janse, C.J., Scherf, A., and Waters, A.P. (2014). P. berghei telomerase 916 subunit TERT is essential for parasite survival. PloS one 9, e108930.

917 Renaud de la Faverie, A., Guedin, A., Bedrat, A., Yatsunyk, L.A., and Mergny, J.L. (2014). 918 Thioflavin $\mathrm{T}$ as a fluorescence light-up probe for G4 formation. Nucleic acids research 42, e65.

919 Sierra-Miranda, M., Vembar, S.S., Delgadillo, D.M., Avila-Lopez, P.A., Herrera-Solorio, A.M., 920 Lozano Amado, D., Vargas, M., and Hernandez-Rivas, R. (2017). PfAP2Tel, harbouring a noncanonical DNA-binding AP2 domain, binds to Plasmodium falciparum telomeres. Cellular microbiology.

Tanaka, E., Fukuda, H., Nakashima, K., Tsuchiya, N., Seimiya, H., and Nakagama, H. (2007). HnRNP A3 binds to and protects mammalian telomeric repeats in vitro. Biochem Biophys Res Commun 358, 608-614.

Trager, W., and Jensen, J.B. (1976). Human malaria parasites in continuous culture. Science (New York, NY 193, 673-675.

Tuteja, R., and Mehta, J. (2010). A genomic glance at the components of the mRNA export machinery in Plasmodium falciparum. Commun Integr Biol 3, 318-326.

Voss, T.S., Mini, T., Jenoe, P., and Beck, H.P. (2002). Plasmodium falciparum possesses a cell cycle-regulated short type replication protein A large subunit encoded by an unusual transcript. The Journal of biological chemistry 277, 17493-17501.

Wellems, T.E., Panton, L.J., Gluzman, I.Y., do Rosario, V.E., Gwadz, R.W., Walker-Jonah, A., and Krogstad, D.J. (1990). Chloroquine resistance not linked to mdr-like genes in a Plasmodium falciparum cross. Nature 345, 253-255.

WHO (2020). World Malaria Report 2020.

Windgassen, M., and Krebber, H. (2003). Identification of Gbp2 as a novel poly(A)+ RNA-binding protein involved in the cytoplasmic delivery of messenger RNAs in yeast. EMBO reports 4, 278283.

Wisniewski, J.R., Zougman, A., Nagaraj, N., and Mann, M. (2009). Universal sample preparation method for proteome analysis. Nature methods 6, 359-362.

Yang, J., Yan, R., Roy, A., Xu, D., Poisson, J., and Zhang, Y. (2015). The I-TASSER Suite: protein structure and function prediction. Nature methods 12, 7-8.

Zakian, V.A. (2012). Telomeres: the beginnings and ends of eukaryotic chromosomes. Exp Cell Res 318, 1456-1460.

Zhang, M., Wang, C., Otto, T.D., Oberstaller, J., Liao, X., Adapa, S.R., Udenze, K., Bronner, I.F., Casandra, D., Mayho, M., et al. (2018). Uncovering the essential genes of the human malaria parasite Plasmodium falciparum by saturation mutagenesis. Science (New York, NY 360.

Zhao, N., Gong, P., Li, Z., Cheng, B., Li, J., Yang, Z., Li, H., Yang, J., Zhang, G., and Zhang, X. (2014). Identification of a telomeric DNA-binding protein in Eimeria tenella. Biochem Biophys 952 


\section{Figure 1}

A

$\underline{k b}$

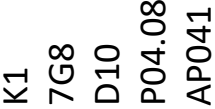

5

1.5

1.0

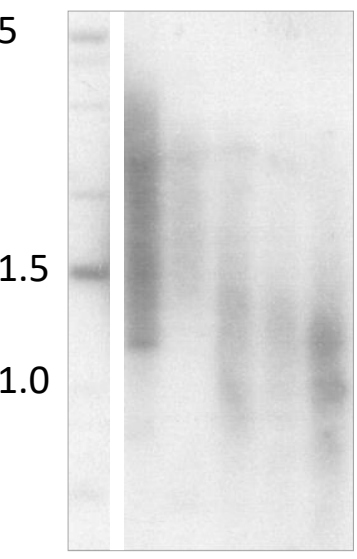

B

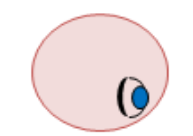

1)Parasites grown in vitro

(9)

(6)

2)RBC lysis and retrieval of parasites

- 3)Fixation of parasites and isolation of nuclei

4) Chromatin cross-linked in formaldehyde to preserve interactions

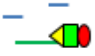

5) Fixed chromatin fragmented by sonication
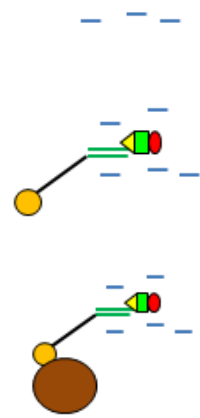

6) Telomeric fragments bind to desthiobiotin-conjugated probe

7) Desthiobiotin binds to magnetic streptavidin beads

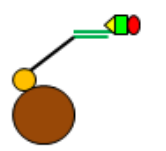

8) Magnetic isolation of streptavidin/probe/chromatin complex

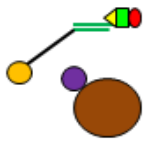

9) Free biotin displaces desthiobiotin due to higher affinity for streptavidin

10) Magnetic removal of streptavidin/biotin complex

11) Precipitation of proteins

12) Reverse cross-linking (SDS, 2mercaptoethanol), sample analysed using mass spectrometry 


\section{Figure 2}

A

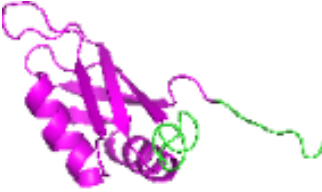

RRM1
RRM2

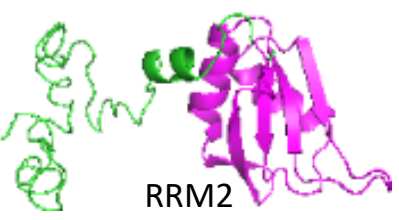

C

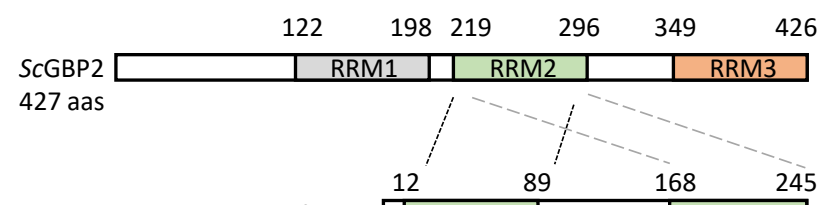

PfGBP2

246 aas

\begin{tabular}{|l|l|l|l|}
\hline & ScRRM1 & ScRRM2 & ScRRM3 \\
\hline PfRRM1 & $33.3,50.0$ & $38.5,57.7$ & $19.8,35.8$ \\
\hline PfRRM2 & $21.8,34.5$ & $25.5,38.7$ & $23.4,35.5$ \\
\hline
\end{tabular}

B

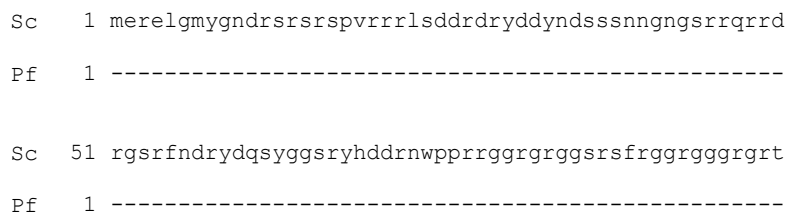

Sc 101 lgpiverdlerqfdatkrnfensifvrnltfdctpedlkelfgtvgevve

SC 151 adiitskghhrgmgtveftknesvqdaiskfdgalfmdrklmvrqdnppp $\mid \ldots:$ : $\mid$ |

Pf 1 - MSMENNSP-
Sc 201 eaakefskkatreeidngfevfiinlpysmnwqslkdmfkecghvlradv

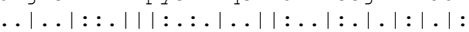
Pf $9-1$ SKGCRVYVGNLPWKVTWPILKNHMKKAGDVVRVDI RRM1

SC 251 eldfngfsrgfgsviyptedemiraidtfngmevegrvlevre------g $\ldots|| ..|:| .|| ..|.| .:|\ldots|$.. . . . . .: : . . : : : | || |

Pf 44 FEDTQGRSKGCGIVEYATYEEAQEAISSLNDSKLEDRLIFVREDREENSG

SC 295 rfnkrknnd----------------ryngrredl-------edtrgtep $.||||. . \mid$ : $|\ldots||:|$ $\mid$.. |

Pf 94 NFEKRKFNNVRKDKFYESRRRRDYDYRKEYRRDDYRRDFRRDEFRRG---

SC 321 glaqdaavhidetaakftegvnpggd------rncfiycsnlpfstarsd Pf 141 - $\ldots \ldots \ldots|\ldots.| \ldots|\quad||: \quad||| \ldots \ldots|| \mid \ldots \ldots$. RRM2

Sc 365 lfdlfgpigkinnaelkpqengqptgvavveyenlvdadfcigklnnyny $||||. \ldots|: \ldots|:|| .::|\ldots \ldots.| \ldots|| \ldots:|\ldots| \ldots|| \ldots \mid:$

Pf 184 LKDLFRKHGRVVRADLKNEDNSSKELIGVVIMENEYEAKNAIDALNFCNF

SC 415 ggeslqisyarrd 427

Pf 234 DGYILKVNYENNE 246 
Figure 3

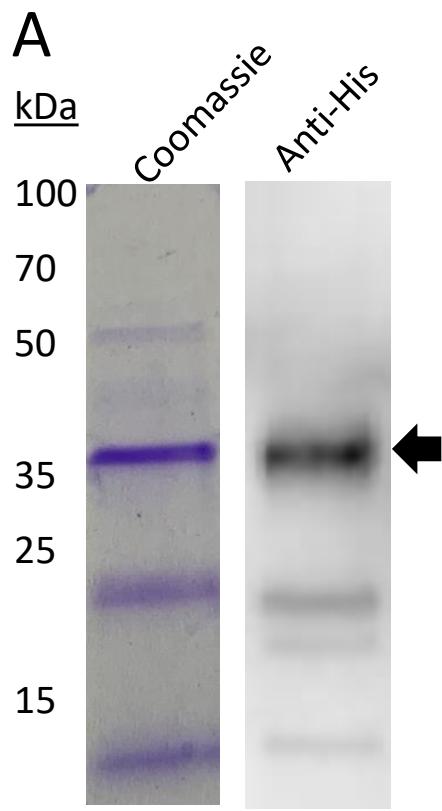

B

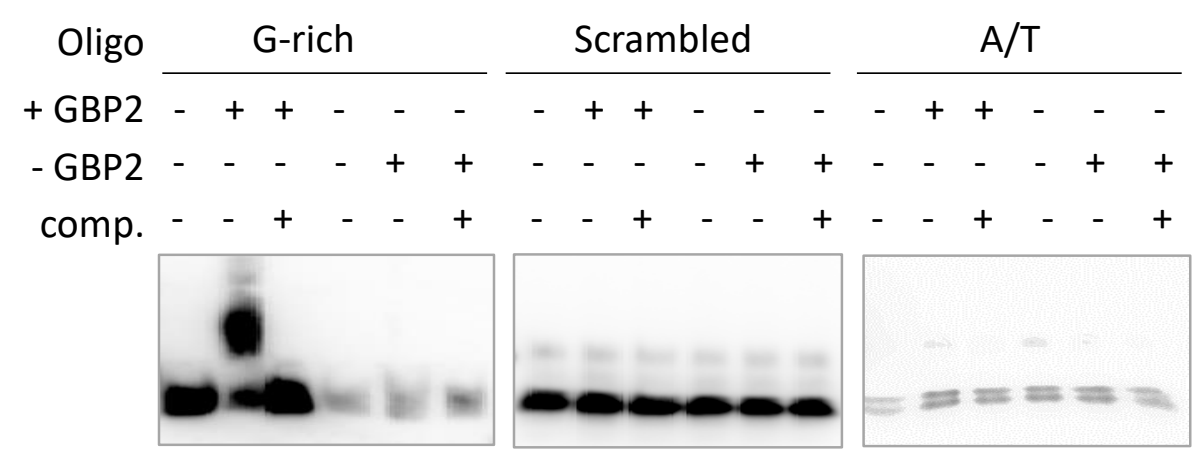

G-rich

Scrambled $\mathrm{A} / \mathrm{T}$
TTCAGGGTTCAGGGTTCAGGGTTCAGGGTTC

GTGTATGCGTTATGTGTATGCGTGTGAGTG TTAAAATTTATAATTATAAATTTTAA

C

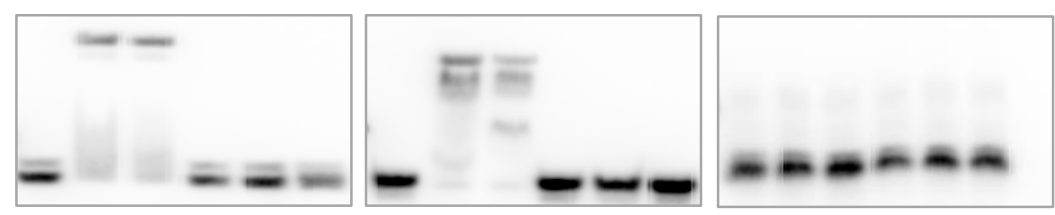

G-rich A/U
UUCAGGGUUCAGGGUUCAGGGUUCAGGGUUC UUAAAAUUUAUAAUUAUAAAUUUUAA 
Figure 4

A

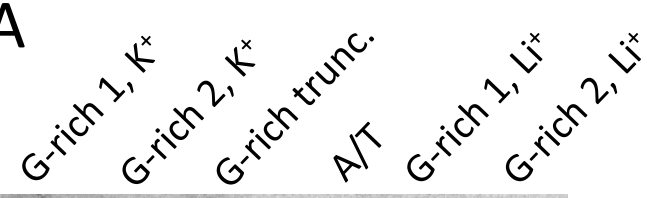

$\mathrm{C}+\underset{\mathrm{BG} 4}{\mathrm{GBP}}+++$

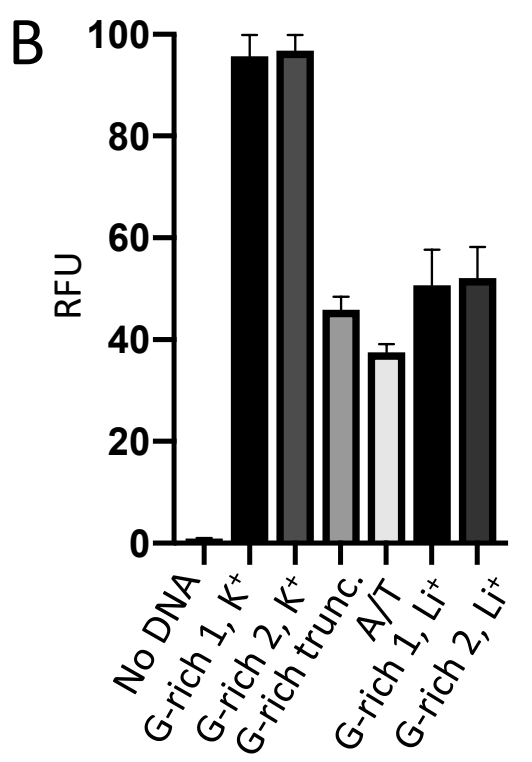

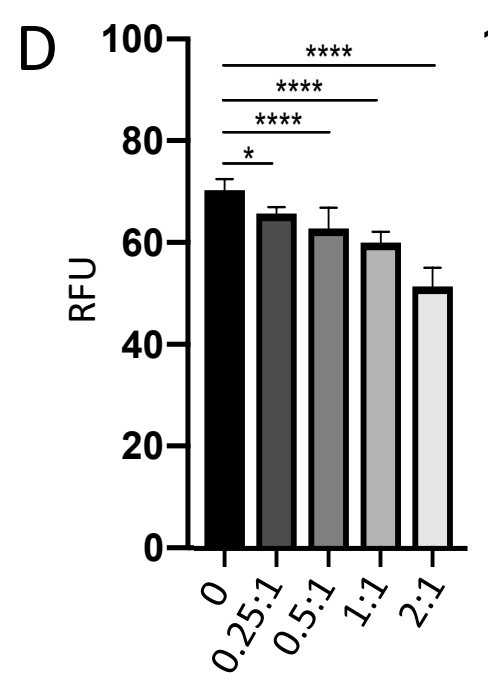

GBP2: DNA

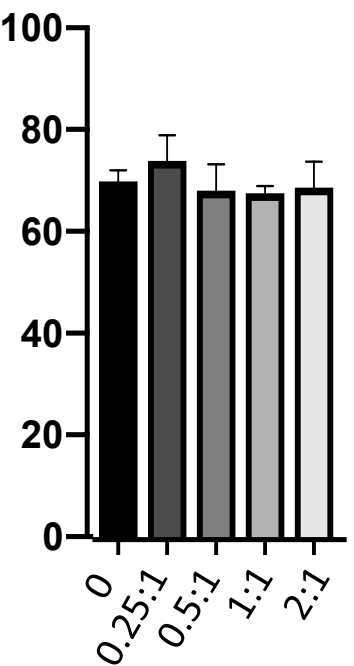

BSA: DNA 
Figure 5

A

Ring Trophozoite Schizont

cyt nuc chr cyt nuc chr cyt nuc chr

GBP2-3HA

$-\quad \longrightarrow$ Histone $\mathrm{H} 4$

$-\quad-\quad$ GAPDH

C

Ring Trophozoite

cyt nuc chr cyt nuc chr

- $-\ldots$ GBP2-2Ty

$\longrightarrow$ HP1-3HA

$-\quad-$ Histone H4

B

Ring Early schizont Late schizont
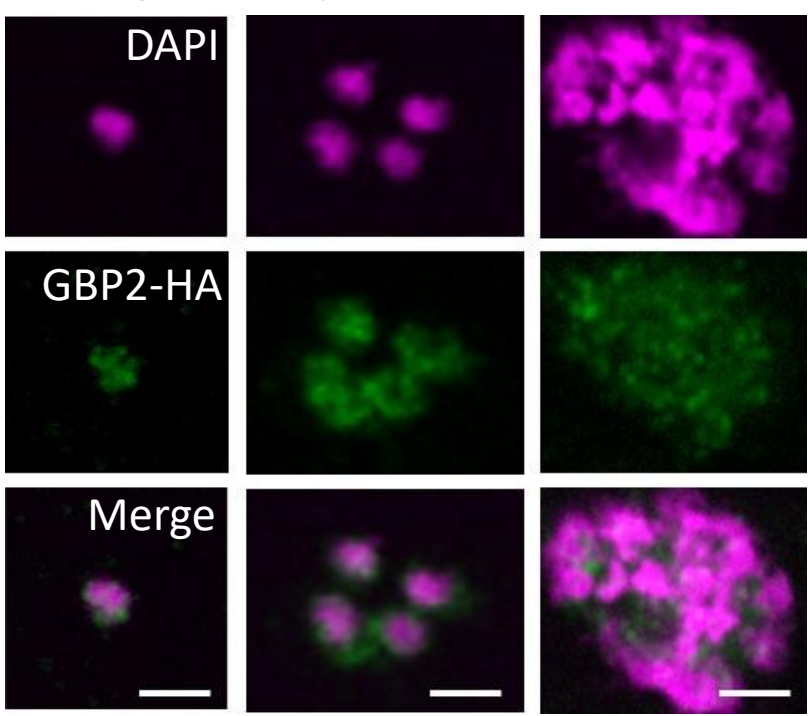

D
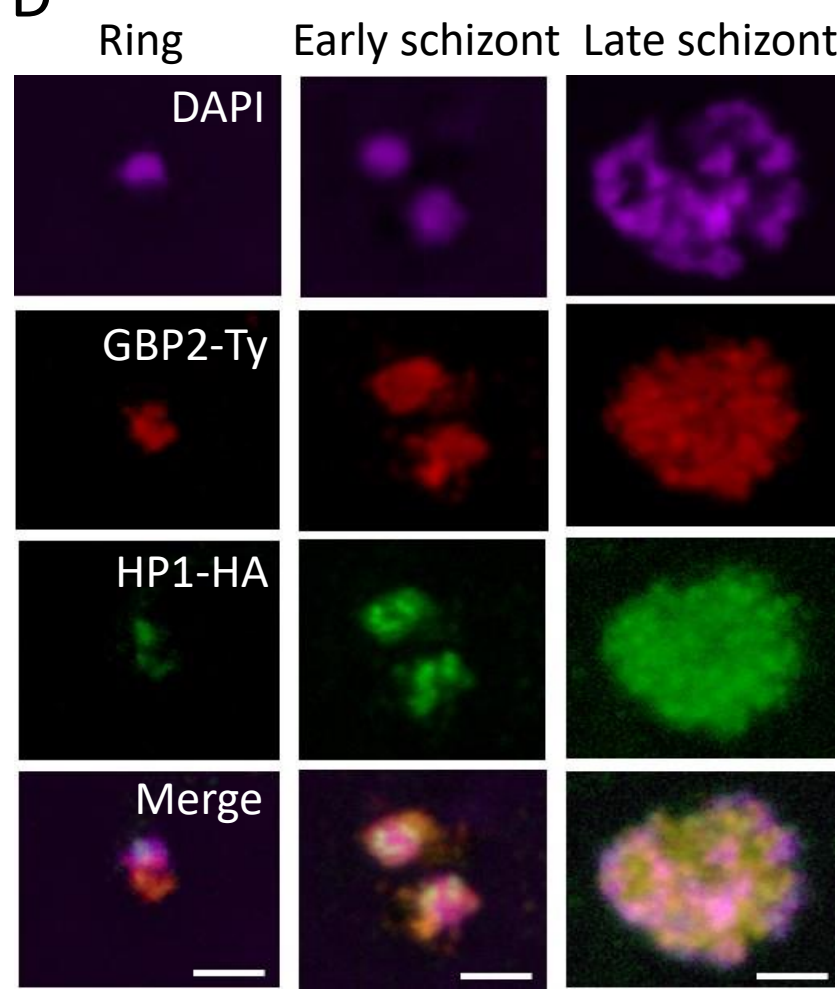
Figure 6

A

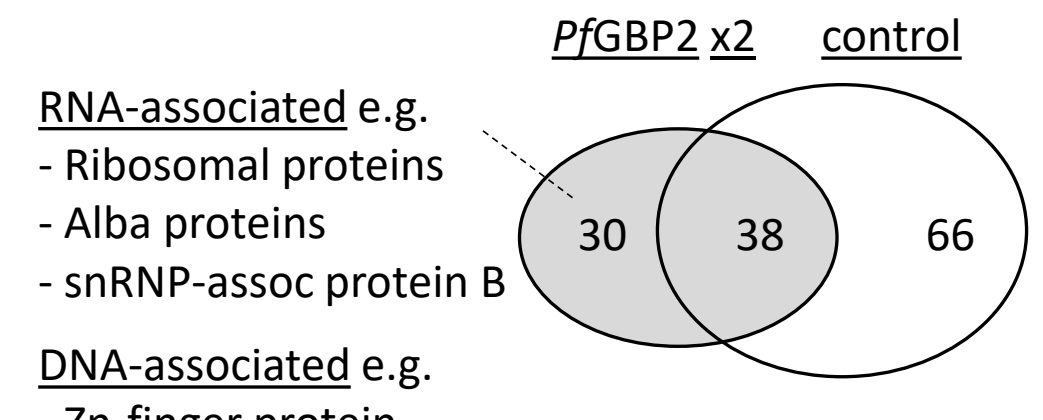

- Zn-finger protein

B

RNA-associated e.g.

- RNA methyltransferases

- splicing factors

- transl. initiation factors

DNA-associated e.g.

- AP2 transcription factors

- chromatin proteins

- HMGB1 


\section{Figure S1}

A

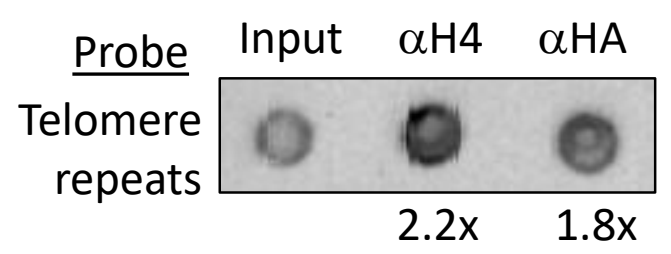

Single gene (PfWRN)

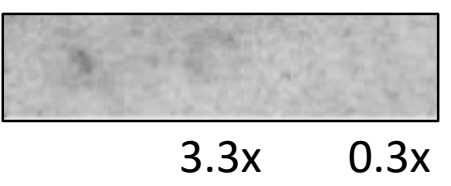

B

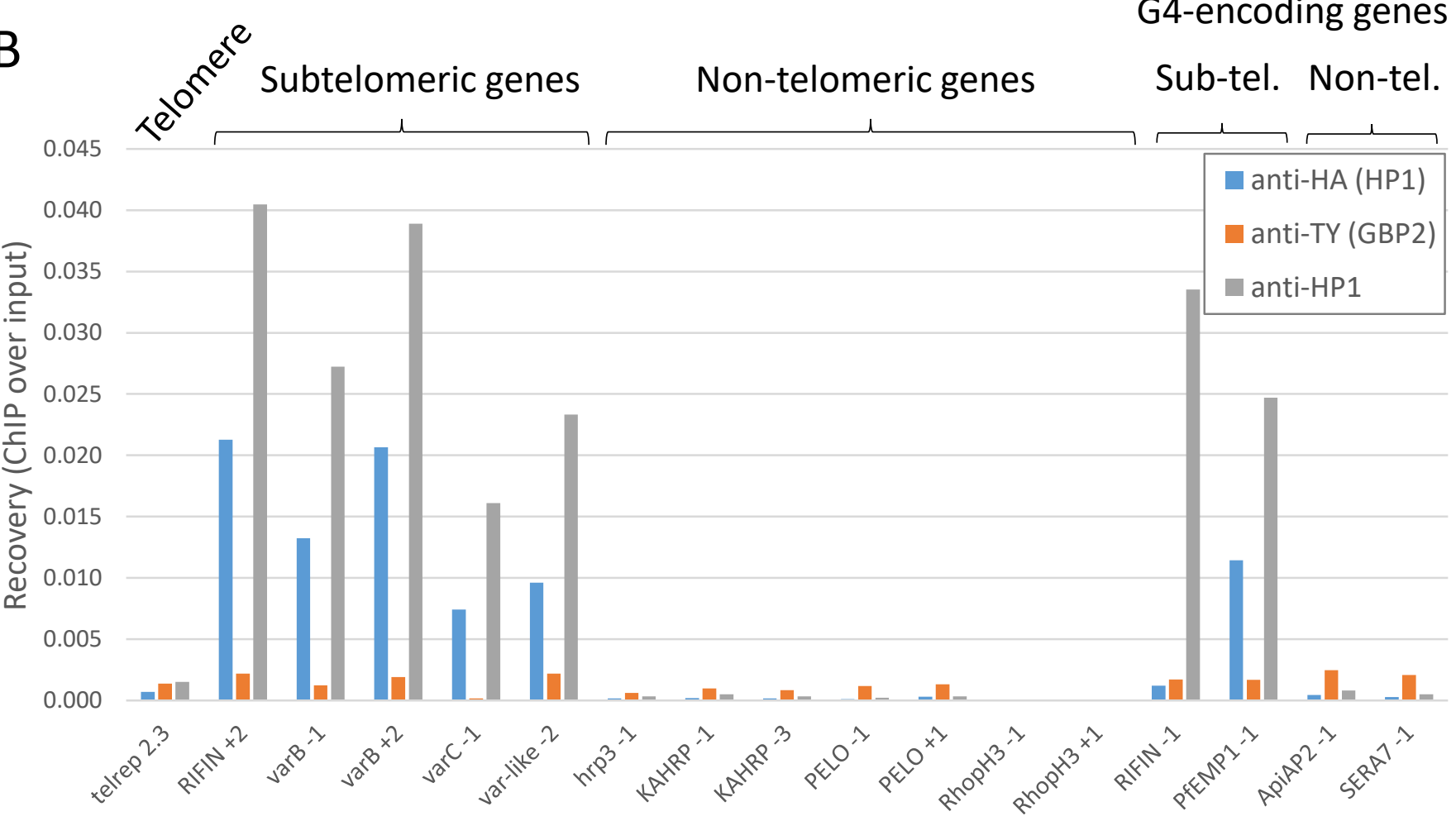

G4-encoding genes Sub-tel. Non-tel. 